\section{Brown pelican threat to space shuttle}

MAJOR alterations may be required in the flight path of the US space shuttle delivery system, whose first flight is due next summer. This follows the discovery that its planned descent route could threaten the habitat of an officially endangered species, the brown pelican.

The only significant breeding grounds of the brown pelican on the west coast of the US are on the Anacapa Islands, 20 miles off the coast of southern California. On present plans, the space shuttle will pass over the islands-still at supersonic speed-on its descent to the Edwards Air Force Base, north of Los Angeles.

Studies are now being carried out by the biology department at the University of San Diego and sponsored by the US Air Force, which is responsible for the shuttle delivery system, on the effect of noise disturbance on the brown pelican's breeding habits. The Department of the Interior's Fish and Wildlife Service will then decide whether it considers the space shuttle will jeopardise the survival of the brown pelican.

As the law stands at present, a ruling that the space shuttle did pose a threat would require the Air Force to change its plans, possibly by altering the descent flight path. In a letter to Senator John Culver of Iowa earlier this year, the Fish and Wildlife Service said that the space shuttle was one of a number of projects which posed "potential consultation problems".

However under an amendment to the 1973 Endangered Species Act introduced by Senator Culver and accepted by the Senate last week, with the strong possibility of becoming law by mid-autumn, cases where the Department of the Interior and another government agency cannot agree on steps to preserve an endangered species could be referred to a seven-person arbitration committee.

Moves to set up such a committee, which would have power to exempt certain projects from the provisions of the Act, follow criticism of the Act's inflexibility. This was illustrated most dramatically in last month's decision by the Supreme Court that the Tennessee Valley Authority could not complete the multi-million dollar Tellico Dam as this threatened to extinguish a three-inch species of fish, the snail darter.

In agreeing to extend the En-
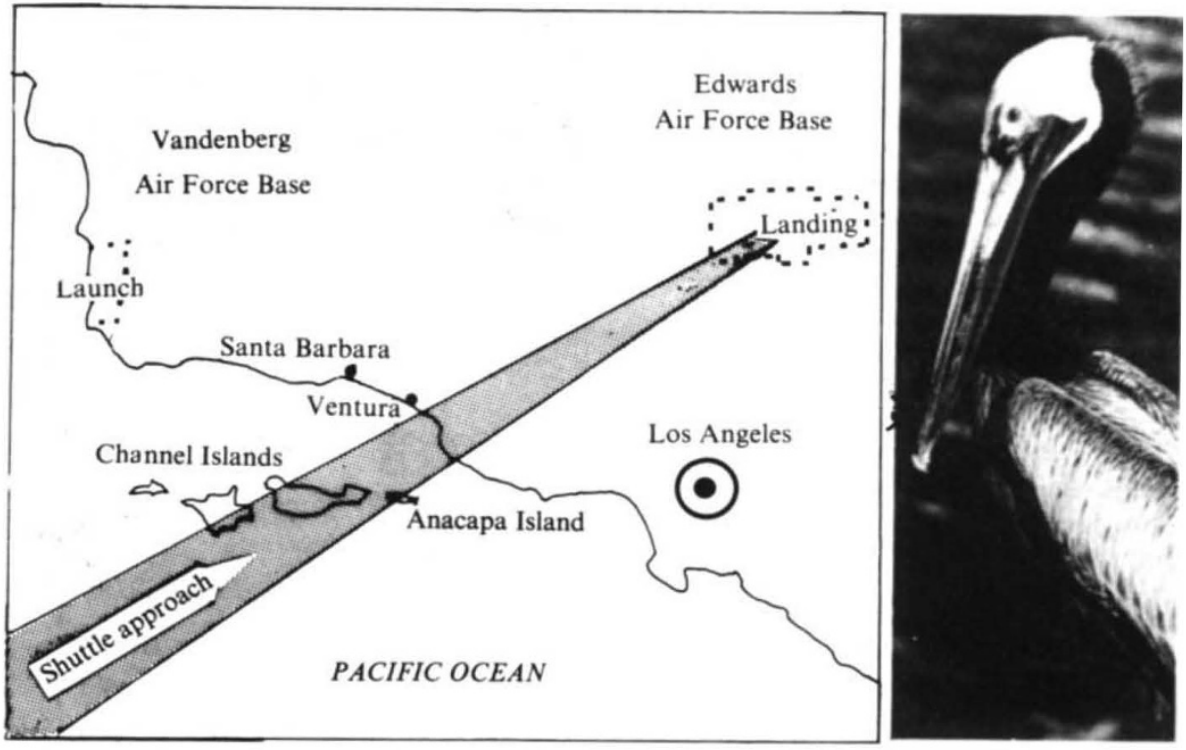

dangered Species Act for a further three years, the Senate rejected a stronger amendment under which any restrictions on a federal project in order to protect an endangered species would have to be justified on social and economic grounds. However it also rejected pleas from both environmentalists and the administration that the Act should be left intact, and that any weakening would seriously undermine its usefulness.

If, as seems likely, a similar amendment is accepted by the House of Representatives, the amendment could be signed into law by President Carter within a few months. The first case for consideration by the committee could well be the snail darter; but the brown pelican is also among potential candidates for consideration.

\section{Precarious population}

Recent measures to protect the brown pelican on the East Coast, and in particular on the coast of Florida, have reversed the decline in population. But on the West Coast the future of the subspecies known as the California brown pelican remains precarious.

This year, for example, although the colony on Anacapa Island includes several hundred pairs of birds, no eggs have been hatched, possibly due to a shortage in fish supply. One Fish and Wildlife Service official said last week that the species was "hanging on by its fingernails in California".

Two aspects of the space shuttle flight path are causing concern. The first is the pressure of the supersonic boom. which could cause the eggs to crack. The second is the disturbance to the pelicans during the nesting season-which normally extends from February into July. However, the Air Force could argue that, with a reason- able number of brown pelicans now enjoying stable existence elsewhere in the US, as well as major breeding grounds on the Pacific coast of Mexico, the space shuttle disturbances would not put the whole species at risk.

Such an argument could well receive a more sympathetic hearing from an arbitration committee, able to bring broader social and economic factors into consideration, than by the Department of the Interior, whose judgement on the potential threat of a project would be based on biological and ecological grounds.

\section{David Dickson}

- A warning that the intrusion of human activities into the natural environment, in particular the increasing destruction of large areas of tropical rain forest, could lead to the disappearance of hundreds of thousands of unique and irreplaceable life-forms is given in a report published last week in Washington by the Worldwatch Institute.

Less than half-and possibly as few as $15 \%$ - of the world's natural species have been recorded in the scientific literature, according to Erik Eckholm, author of the report Disappearing species: the social challenge. He adds: "If current patterns of human activity continue, a good share of the unrecorded majority of species will vanish before their existence, much less their biological importance or economic utility, is known."

He suggests a massive expansion of the UNESCO Biosphere Reserve system. So far, 144 Biosphere Reserves have been established in 35 countries, but tropical ecosystems are badly unrepresented. Mr Eckholm recommends a strategy by which nature-reserve needs are identified country by country, and governments then encouraged to establish them. 